\title{
MODIFIKASI SISTEM PEMIKAT CAHAYA KEDIP PADA BUBU TERHADAP HASIL TANGKAPAN IKAN DI PERAIRAN SIBOLGA
}

\section{Modification of Flash Light Attractor on Fish Trap to Fish Catch in Sibolga Waters}

\author{
Oleh: \\ Juni Susanti Banurea ${ }^{1 *}$, Melani Manurung ${ }^{2}$ \\ ${ }^{1}$ Program Studi Pemanfaatan Sumberdaya Perairan, Sekolah \\ Tinggi Perikanan Sibolga, Sibolga, Indonesia \\ ${ }^{2}$ Program Studi Pemanfaatan Sumberdaya Perikanan, \\ Sekolah Tinggi Perikanan Sibolga, Sibolga, Indonesia \\ ${ }^{*}$ Korespondensi penulis: junisusanti23@gmail.com
}

\begin{abstract}
ABSTRAK
Penelitian ini bertujuan untuk mengetahui hasil tangkapan ikan karang dengan penggunaan atraktor cahaya berkedip dalam bubu dan membandingkan hasil tangkapan tanpa menggunakan cahaya berkedip. penelitian ini dilaksanakan pada bulan Januari di perairan Labuan Angin, kecamatan Tapanuli Tengah dengan menggunakan metode eksperimen. Data dikumpulkan dari 3 unit bubu yang dipasangkan cahaya berkedip. Hasil tangkapan bubu selama penelitian berjumlah 56 ekor ikan Hasil tangkapan yang diperoleh 37 ekor ikan tertangkap menggunakan bubu lampu berkedip dan 19 ekor ikan tertangkap menggunakan bubu tanpa cahaya berkedip. Hasil analisis uji menunjukkan efek yang tidak sama konkret terhadap hasil tangkapan antara bubu menggunakan cahaya berkedip dan bubu tanpa cahaya berkedip.
\end{abstract}

Kata kunci: atraktor, bubu, cahaya berkedip, ikan karang

\section{ABSTRACT}

This study aims to determine the catch of reef fish using light attractors in fish trap and to compare the catches without using flashing lights. This research was conducted in January in Labuan Angin waters, Tapanuli Tengah Disrict using experimental method. The data from 3 traps units that are paired with the lights flashes. The traps cought during the study were 56 fishes. The catch obtained was that 37 fishes were cought using flashing lights and 19 fish were cought without using flashing lights. The results of the test analysis showed a different effect on the catch between traps with blinking light and traps without blinking light.

Key words: attractors, traps, flashing lights, reef fish

\section{PENDAHULUAN}

Ekosistem terumbu karang merupakan habitat ikan yang memiliki produktivitas yang tinggi (Fachruqi et al. 2019). Banyaknya jenis komoditas ikan bernilai ekonomis tinggi hidup dalam habitat ini, hal ini menyebabkan daerah perairan terumbu karang menjadi lokasi kegiatan perikanan oleh sebagian besar masyarakat pesisir dengan menggunakan alat tangkap bubu. Lebih lanjut, saat ini alat tangkap bubu menggunakan terumbu karang untuk pemberat dan juga sebagai penyamaran (kamuflase) menyebabkan kerusakan terumbu karang itu sendiri (Iskandar 2011).

Upaya pemanfaatan daerah perairan dengan metode tersebut mengakibatkan kondisi terumbu karang yang semakin lama akan semakin rusak sehingga menyebabkan kematian, dan akhirnya berdampak menurunnya kuantitas hasil tangkapan (Gustaman et al. 2016). Upaya untuk tetap menarik 
perhatian ikan melalui penyamaran dengan terumbu karang dapat diganti dengan memanfaatkan sifat biologi dari ikan yang cenderung tertarik dengan cahaya/fototaksis positif (Reppie et al. 2016).

Penggunaan alat bantu penangkapan dengan pemikat cahaya (light attractor) untuk meningkatkan hasil tangkapan bubu cenderung lebih efektif dan efisien bila dibandingkan dengan metode konvesional. Sesuai penelitian (Purbayanto et al. 2010) ikan karang, memakai indra penglihatan dan penciuman ketika mencari makan dan mengikuti keadaan lingkungan sekelilingnya. Hal yang sama disampaikan Janhar (2013) bahwa penangkapan ikan dengan bubu di sekitar karang sebaiknya menggunakan bubu dengan cahaya lampu LED berkedip, agar tidak merusak karang.

Ketertarikan dalam cahaya lebih dikarenakan ikan karang mengandalkan indra penglihatannya untuk melihat eksistensi ikan-ikan kecil yang menjadi produsennya. Hal ini sesuai dengan hasil penelitian Aminah dan Ahmadi (2017) dan Yudha (2018) bahwa penggunaan lampu LED dapat memikat ikan pada alat tangkap bagan; purse seine (Sulaiman et al. 2015); dan alat tangkap bubu. Penelitian selanjutnya menjelaskan bahwa rangsangan dapat untuk menarik perhatian ikan ke dalam suatu area penangkapan, berupa rangsangan penglihatan, kimiawi, pendengaran, listrik dan tempat berlindung (Purbayanto et al. 2010).

Penggunaan lampu LED dapat menjadi solusi yang bagus, karena LED memiliki karakteristik hemat energi, ramah lingkungan, mudah dikontrol dan mampu bekerja dalam waktu yang lama (Baswantara et al. 2017). Jika dibandingkan dengan sumber cahaya lain LED masih lebih baik sesuai hasil penelitian Khairul et al. (2017) dengan hasil bagan uji coba lampu LED biru menangkap enam spesies sedangkan lampu neon menangkap empat spesies. Yudha et al. (2015), bubu dengan atraktor cahaya warna merah memperoleh hasil tangkapan 19 ekor ikan kerapu sedangkan bubu tanpa atraktor cahaya warna merah lima ekor ikan kerapu. Tujuan penulisan ini adalah untuk mengetahui komposisi hasil tangkapan dan menganalisis perbedaan hasil tangkapan bubu kawat menggunakan pemikat cahaya berkedip dan tanpa menggunakan cahaya berkedip di perairan Sibolga.

\section{METODE PENELITIAN}

Penelitian ini dilakukan mulai bulan Januari sampai bulan Oktober 2020 di perairan Pangkalan Pendaratan Ikan Labuan Angin Kecamatan Tapian Nauli. Pemilihan lokasi penelitian didasarkan karena perairan PPI (Pangkalan Pendaratan Ikan) Labuan Angin dikelilingi oleh mangrove dengan kedalaman perairannya $\pm 4-6$ meter. Alat dan bahan yang digunakan dalam penelitian ini: bubu kawat, lampu LED, tali, batu, kabel dan kamera.

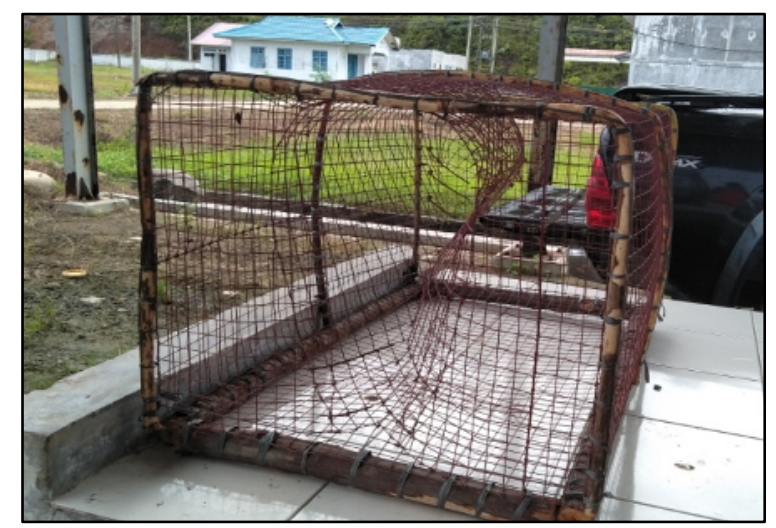

Gambar 1 Bubu Kawat 


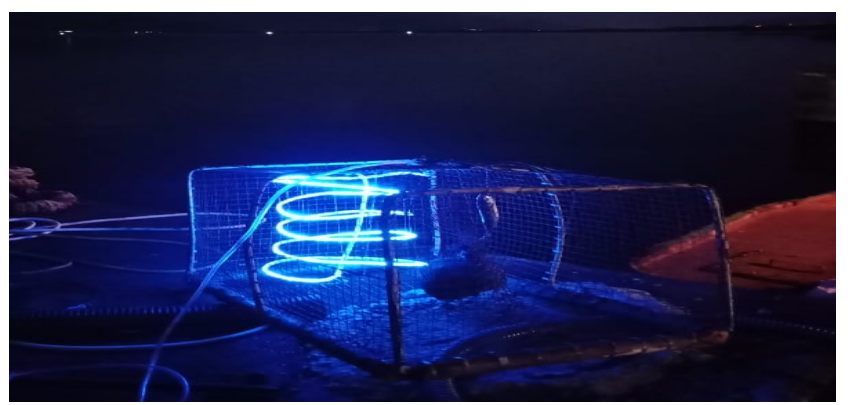

Gambar 2 Bubu Kawat Menggunakan Lampu Berkedip

Pengumpulan data yang dilakukan pada saat penelitian adalah dengan metode eksperimen berupa tangkapan dari tiap perlakuan yang diberikan dan data parameter perairan saat sampling. Data sekunder adalah data yang diperoleh dari data tangkahan setiap kapal bubu yang mendarat dan tinjauan literatur atau instansi pemerintah yang terkait dengan kegiatan penelitian ini.

Data yang diperoleh selama penelitian dari dua perlakuan dan tiga kali ulangan dengan menggunakan metode experimental fishing, maka jumlah hasil tangkapan bubu kawat pada perlakuan menggunakan lampu LED, menggunakan bubu kawat, dianalisis dengan menggunakan penelitian komparatif.

\section{HASIL DAN PEMBAHASAN}

\section{Hasil Tangkapan Bubu Menggunakan Pemikat Cahaya Berkedip}

Hasil penelitian yang dilakukan selama kurang lebih satu bulan di perairan Labuan Angin Tapanuli Tengah dalam pengoperasian bubu kawat dengan menggunakan pemikat cahaya berkedip, terdapat beberapa jumlah hasil tangkapan pada masing-masing unit percobaan. Jenis ikan yang tertangkap pada alat tangkap bubu ini merupakan ikan-ikan demersal di antaranya ikan jarang gigi, ikan kerapu, ikan baronang, kepiting ikan tanda. Secara rinci hasil tangkapan selama penelitian disajikan pada Tabel 1.

Tabel 1 Jenis Hasil Tangkapan Bubu Kawat

\begin{tabular}{lll}
\hline \multicolumn{1}{c}{ Nama Daerah } & \multicolumn{1}{c}{ Nama Indonesia } & \multicolumn{1}{c}{ Nama Ilmiah } \\
\hline Cabe-cabe & Baronang & Siganus Sp. \\
Tando-tando & Tanda-tanda & Lutjanus Mahogoni \\
Jarang Gigi & Jambian (Jarang Gigi) & Lutjanus Argentimaculatus \\
Kerapu & Kerapu & Epinephelus coioides \\
Kepiting & Kepiting & Brachyura \\
\hline
\end{tabular}

Jumlah hasil tangkapan bubu kawat yang diperoleh dari dua perlakuan dan tiga kali ulangan berjumlah 56 ekor dari 5 jenis ikan, di mana bubu kawat menggunakan lampu berkedip memperoleh hasil tangkapan dengan jumlah 37 ekor ikan, bubu kawat dengan tidak menggunakan lampu LED memperoleh hasil tangkapan dengan jumlah 19 ekor. Untuk lebih jelasnya jumlah individu ikan hasil tangkapan bubu kawat dapat kita lihat pada Tabel 2.

Berdasarkan hasil tangkapan ikan pada tiap-tiap perlakuan dan ulangan, maka jumlah hasil ikan tangkapan bubu kawat selama penelitian dapat kita lihat pada Gambar 3.

Berdasarkan hasil tangkapan ikan pada tiap-tiap perlakuan dan ulangan, maka jumlah rata-rata ikan hasil tangkapan bubu kawat setiap perlakuan dapat kita lihat pada Gambar 4. 
Tabel 2. Jumlah Hasil Tangkapan Bubu Kawat

\begin{tabular}{clll}
\hline \multirow{2}{*}{ Ulangan } & \multicolumn{2}{c}{ Perlakuan } & \multirow{2}{*}{ Jumlah } \\
\cline { 2 - 3 } & LED (attractor) & Non LED & \\
\hline 1 & 9 & 8 & 17 \\
2 & 15 & 6 & 21 \\
3 & 13 & 5 & 18 \\
Jumlah & 37 & 19 & 56 \\
Rata-rata & 12,3 & 6,3 & \\
\hline
\end{tabular}

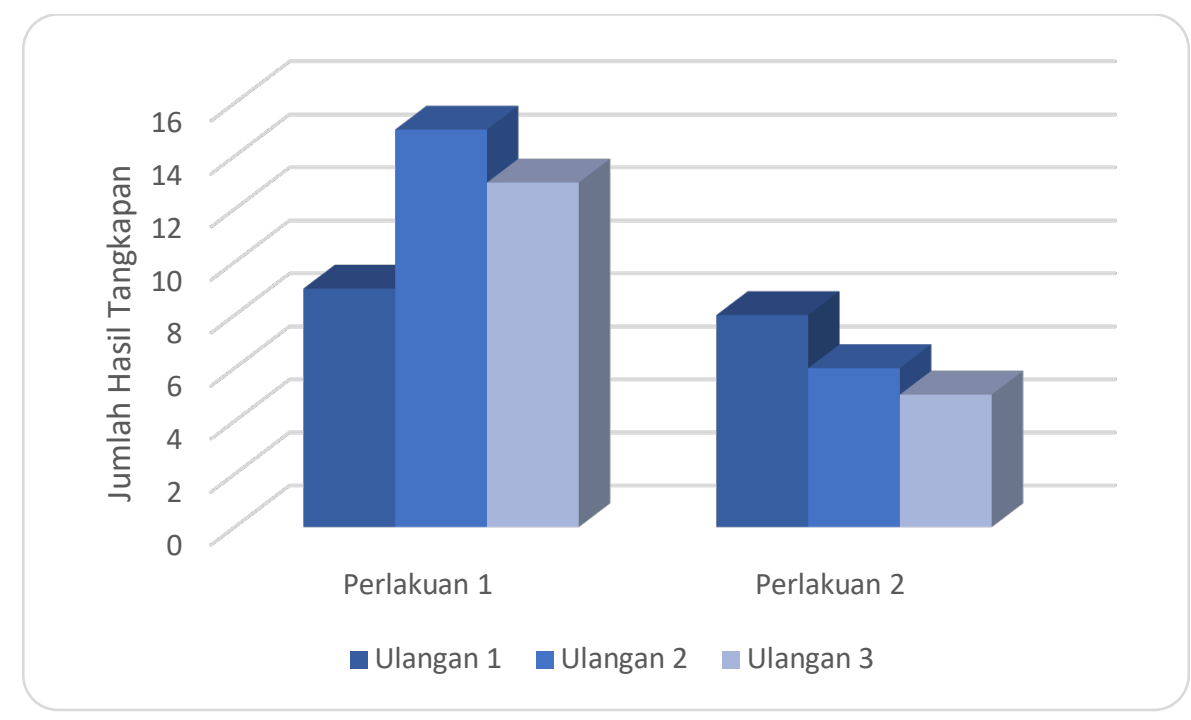

Gambar 3 Jumlah Hasil Tangkapan (ekor) Tiap Perlakuan dalam Tiga Ulangan

\section{Rata-rata Tiap Perlakuan}

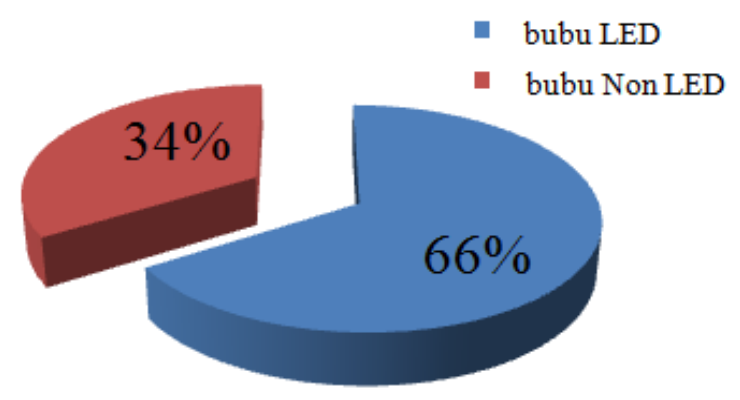

Gambar 4 Jumlah Hasil Tangkapan Tiap Perlakuan

Berdasarkan histogram dari gambar di atas, dapat terlihat jelas perbedaan jumlah rata-rata hasil tangkapan bubu kawat tiap perlakuan, di mana perlakuan pertama dengan menggunakan bubu kawat lampu LED memperoleh rata-rata jumlah hasil tangkapan 12 ekor ikan tiap ulangan, bubu kawat pada perlakuan dua menggunakan lampu LED berjumlah rata-rata hasil tangkapan lima ekor ikan tiap ulangan, bubu kawat tidak menggunakan lampu LED memperoleh jumlah rata-rata hasil tangkapan delapan ekor ikan tiap ulangan.

\section{Jenis dan Jumlah Ikan Hasil Tangkapan Bubu Kawat}

Berdasarkan dari hasil penelitian di lapangan, maka jumlah hasil tangkapan dari bubu kawat setiap perlakuan dapat kita lihat pada Tabel 3 di bawah ini. 
Tabel 3 Jumlah Ikan Hasil Tangkapan Bubu Kawat Tiap Perlakuan

\begin{tabular}{lccc}
\hline \multirow{2}{*}{ Jenis Ikan } & \multicolumn{2}{c}{ Perlakuan } & \multirow{2}{*}{ Jumlah } \\
\cline { 2 - 3 } & LED (attractor) & Non LED & \\
\hline Baronang & 14 & 11 & 25 \\
Tanda-tanda & 10 & 6 & 16 \\
Jambian (Jarang Gigi) & 3 & 2 & 5 \\
Kerapu & 2 & 1 & 3 \\
Kepiting & 3 & 3 & 6 \\
Jumlah & 32 & 23 & 56 \\
Rata-rata & 6,4 & 4,6 & \\
\hline
\end{tabular}

Berdasarkan Tabel 3 di atas maka jenis dan jumlah hasil tangkapan bubu kawat dapat dilihat pada Gambar 5 di bawah ini.

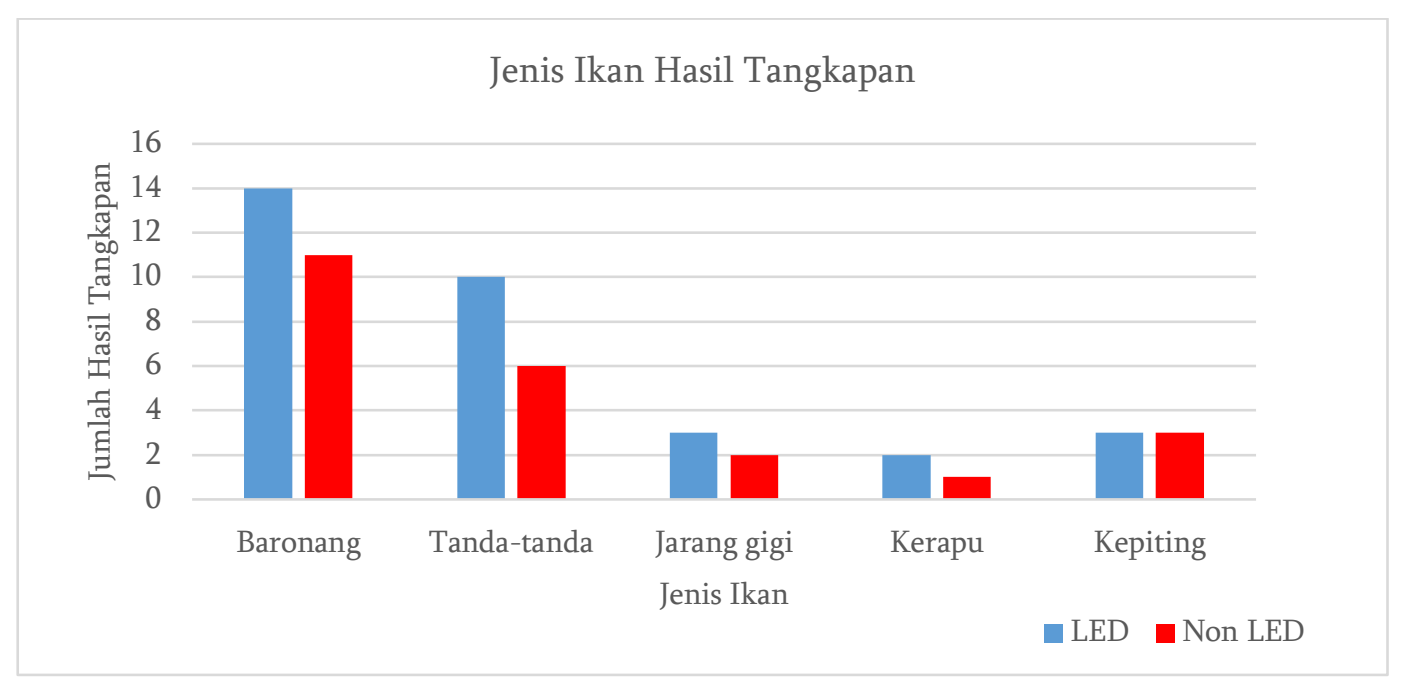

Gambar 5 Histogram Jenis dan Jumlah Ikan Hasil Tangkapan

Berdasarkan Gambar 5, dapat terlihat jenis dan jumlah ikan hasil tangkapan pada perlakuan pertama bubu kawat menggunakan lampu berkedip (LED) di mana ikan baronang yang tertangkap berjumlah 14 ekor, tanda-tanda berjumlah 10 ekor, ikan jarang gigi tiga ekor, ikan kerapu dengan hasil tangkapan berjumlah dua ekor dan kepiting tiga ekor Pada perlakuan kedua bubu kawat tidak menggunakan LED (non LED) mendapatkan hasil tangkapan ikan baronang dengan jumlah 11 ekor, ikan tanda-tanda hasil tangkapan berjumlah enam ekor, ikan jarang gigi berjumlah dua ekor, ikan kerapu berjumlah satu ekor dan kepiting sebanyak tiga ekor.

\section{Pengaruh Light Attractor Berkedip pada Bubu terhadap Hasil Tangkapan}

Berdasarkan hasil pengamatan selama penelitian yang dari dua perlakuan dan tiga ulangan, perbedaan pemikat cahaya pada bubu kawat membuktikan bahwa ada pengaruh terhadap hasil tangkapan dari jumlah hasil tangkapan masing-masing bubu kawat. Sesuai dengan hasil tangkapan selama penelitian jumlah hasil tangkapan terbanyak pada alat tangkap bubu kawat dengan menggunakan lampu berkedip (LED) dengan jumlah hasil tangkapan berjumlah 37 ekor dalam dua perlakuan tiga kali ulangan dengan rata-rata hasil tangkapan 12 ekor tiap ulangan. Selanjutnya hasil tangkapan bubu kawat tidak menggunakan lampu berkedip (non LED) dengan jumlah hasil tangkapan berjumlah 19 ekor dalam dua perlakuan tiga kali ulangan dengan rata-rata hasil tangkapan enam ekor tiap ulangan. 


\section{Analisis Biaya Pembuatan Bubu Kawat}

Dalam kegiatan pembuatan bubu kawat, yang digunakan berjumlah tiga unit bubu kawat sebagai bahan perlakuan penelitian. Bentuk maupun kontruksi dari bubu yang digunakan pada penelitian tidak jauh berbeda dengan yang ada di pasar. Analisis pembuatan bubu dapat dilihat pada Tabel 4 berikut.

Tabel 4 Analisis Biaya Pembuatan Satu Unit Bubu Kawat

\begin{tabular}{lllrrr}
\hline \multirow{2}{*}{ Uraian } & \multicolumn{3}{c}{ Jumlah } & \multirow{2}{*}{ Harga (Rp) } & \multicolumn{1}{c}{ Jumlah } \\
\cline { 2 - 3 } & \multicolumn{1}{c}{ Satuan } & Volume & & \\
\hline Bubu & Bubu & 3 & 250.000 & 750.000 \\
Lampu (LED) & Meter & 6 & 200.000 & 1.200 .000 \\
Adaptor & Unit & 1 & 100.000 & 100.000 \\
Kabel & Meter & 20 & 5.000 & 100.000 \\
Tali polyethylene & Meter & 4 & 20.000 & 80.000 \\
\hline Total (Rp) & & & & 2.230 .000 \\
\hline
\end{tabular}

Total harga pengeluaran pembuatan bubu kawat sebanyak tiga unit selama penelitian berjumlah Rp2.230.000. Total harga pembuatan bubu kawat sebanyak tiga unit selama penelitian berjumlah Rp2.230.000 dengan rata-rata harga pembuatan bubu satu unit Rp250.000. Daya tahan dari bubu kawat ini dapat digunakan hingga \pm 4 bulan dengan 20 kali pengoperasian, dan untuk meningkatkan daya tahan kawat bubu perlu dilakukan pengecatan agar daya tahan bubu bisa lebih lama.

\section{KESIMPULAN DAN SARAN}

Berdasarkan hasil penelitian dari dua perlakuan tiga kali ulangan, hasil tangkapan bubu sebanyak 37 ekor dengan menggunakan lampu LED dan berjumlah 19 ekor tidak menggunakan lampu LED. Hasil tangkapan tersebut menunjukkan ada pengaruh penggunaan lampu LED terhadap hasil tangkapan ikan di Perairan Sibolga. Jenis-jenis ikan hasil tangkapan bubu kawat menggunakan pemikat cahaya berkedip antara lain: ikan baronang (Siganus Sp), ikan tanda-tanda (Lutjanus mahogoni) ikan jambian (Lutjanus argentimaculatus), ikan kerapu (Ephinepelus tauvina), dan kepiting (Portunidae).

\section{UCAPAN TERIMA KASIH}

Ucapan terimakasih yang sebesar-besarnya kami ucapkan kepada Badan Riset dan Inovasi Nasional Deputi Bidang Penguatan Riset dan Pengembangan, Kementerian Riset dan Teknologi atas dana hibah penelitian dosen pemula (PDP) yang telah diberikan untuk menyelesaikan penelitian ini. Ucapan terima kasih juga kami sampaikan kepada Sekolah Tinggi Perikanan Sibolga beserta LPPM sebagai instansi dan lembaga yang menfasilitasi kami dalam penelitian ini, juga kepada semua pihak yang terlibat dalam penyelesaian penelitian ini sampai tahap penerbitan artikel ini.

\section{DAFTAR PUSTAKA}

Aminah Siti, Ahmadi. 2017. Studi Komparatif Penggunaan Lampu Pada Kegiatan Penangkapan Ikan di Perairan Martapura. Fish Scientiae. 7(2):216-227.

Janhar AA. 2013. Pengaruh intensitas cahaya Lampu LED Berkedip terhadap Hasil Tangkapan Ikan Karang dengan Bubu di Perairan Pulau Ternate. Aquatic Science \& Management. 1(1):9-44.

Baswantara Arif, Indra J, Roza Y. 2017. Modifikasi dan Rekayasa Rumpon Elektronik Sebagai Alat Bantu Penangkapan Ikan Berbasis Cahaya Led. Jurnal Ilmu dan Teknologi Kelautan Tropis 9(1):201-209. 
Fachruqi W, Muhammad Kurnia, Musbir. 2019. Studi Pemanfaatan Lampu Light Emitting Diode(LED) Bawah Air Sebagai Alat Pemikat Ikan pada Alat Tangkap Bubu. Prosiding Simposium Nasional Kelautan dan Perikanan VI Universitas Hasanuddin (8hal). Makassar.

Gustaman G. Fauziyah, Isnaini. 2016. Efektifitas Perbedaan Warna Cahaya Lampu terhadap Hasil Tangkapan Bagan Tancap di Perairan Sungsang Sumatera Utara. Maspari Jurnal. 4(1):92-102.

Iskandar D. 2011. Analisis Hasil Tangkapan Sampingan Bubu yang dioperasikan di Perairan Karang Kepulauan Seribu. Jurnal Saintek Perikanan.

Khairul, Wazir Mawardi, Mochammad Riyanto. 2017. Penggunaan Lampu Light Emitting Diode(LED) Biru Terhadap Hasil Tangkapan Bagan Apung di Kabupaten Aceh Jaya. ALBACORE 1(2):235243.

Purbayanto A, Riyanto M, Purnama AD. 2010. Fisiologi dan Tingkah laku Ikan pada Perikanan Tangkap. IPB Press. Bogor.

Reppie Emil, Wilhelmina Patty, Meta Sopie1, Kernius Taine. 2016. Pemikat Cahaya Berkedip pada Bubu dan Pengaruhnya terhadap Hasil Tangkapan Ikan Karang. Marine Fisheries. 7(1):25-32.

Sulaiman S, Baskoro MS, Taurusman AA, Wisudo SH, Yusfiandayani R. 2015. Tingkah Laku Ikan pada Bagan Petepete yang Menggunakan Lampu LED. Jurnal Ilmu dan Teknologi Kelautan Tropis. 7(1):205-223.

Yudha I. 2018. Pengaruh Warna Pemikat Cahaya (Light Attractor) Berkedip terhadap Jenis dan Jumlah Ikan Hasil Tangkapan Bubu Karang (Coral Trap) di Perairan Pulau Pahawang, Lampung Selatan.

Yudha PAP, Asriyanto, Pramonowibowo. 2015. Analisis Pengaruh Penggunaan Atraktor Cahaya Warna Merah dan Perbedaan Waktu Pengoperasian Alat Tangkap Bubu Karang Terhadap Hasil Tangkapan Ikan Kerapu (Epinephelinea) di Perairan Karimunjawa. Diponegoro. Universitas Diponegoro. 